DOI 10.37882/2223-2982.2021.05-2.23

\title{
АНАЛИЗ ЯЗЫКОВЫХ СРЕДСТВ ВЕРБАЛИЗАЦИИ КОНЦЕПТА EMPLOYEE В ШАБЛОНАХ РЕЗЮМЕ АНГЛОЯЗЫЧНОГО БИЗНЕС-ДИСКУРСА
}

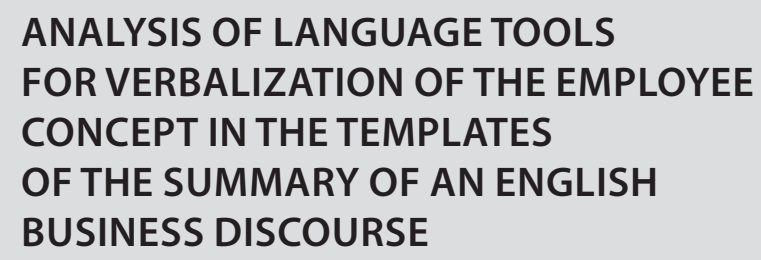

ANALYSIS OF LANGUAGE TOOLS FOR VERBALIZATION OF THE EMPLOYEE CONCEPT IN THE TEMPLATES OF THE SUMMARY OF AN ENGLISH BUSINESS DISCOURSE

\section{A. Pashina}

Summary: The article analyzes the specifics of vocabulary usage and the use of the certain grammatical forms in the resume samples of English-language business discourse. The author points out the extreme importance of the linguistic units of the texts under study and highlights a number of principles for their selection when creating an EMPLOYEE concept frame. The main criterion for selecting the means of verbalization of this concept is the supposed features of a recipient's perception at the primary stage of $\mathrm{CV}$ considering. The relevance of the paper is related to the increasing role of English-language patterns in international business communication.

Keywords: resume, English-language business discourse, frame, concept.
Пашина Алёна Владимировна к.филол.н., доцент, Тюменский индустриальный университет pashinaav@tyuiu.ru

Аннотация: В статье анализируется специфика использования лексики и определенных грамматических форм в шаблонах резюме англоязычного бизнес-дискурса. Автор указывает на предельную важность языковых единиц исследуемых текстов и выделяет ряд принципов их отбора при создании фрейма концепта EMPLOYEE. Ведущим критерием отбора средств вербализации указанного концепта являются предполагаемые особенности восприятия реципиента на первичном этапе обработки CV. Актуальность исследования связана с возрастающей ролью англоязычных паттернов в международной деловой коммуникации.

Ключевые слова: резюме, англоязычный бизнес-дискурс, фрейм, концепт.
3 а более чем 500-летнюю историю резюме [3], его структура претерпела ряд существенных изменений, связанных с трансформацией жизненного уклада общества. В XX веке усиление конкуренции на рынке труда сделало job application (пакет документов, включающих резюме и сопроводительное письмо) самым массовым жанром деловой корреспонденции. К 1950-60 годам резюме сократилось до одной страницы и приобрело вид таблицы. Такие метаморфозы были обусловлены набирающим обороты техническим прогрессом и все ускоряющимся темпом деловой коммуникации. Именно к этому периоду следует отнести зарождение «телеграфного стиля» резюме: «For easier reading and brevity (even in federal resumes), resumes are written in what is called telegraphic style (здесь и далее выделено мной - П.А. ). In essence these words are eliminated but the sentence is still understood / Для удобства чтения и краткости (даже в федеральных резюме) резюме пишутся в так называемом телеграфном стиле. По существу, эти слова устраняются, но предложение все еще понимается « [13].

Уменьшение объема резюме привело к усилению значимости каждого слова: «sharpen up the language on your resume so it leaves a lasting impression / отточите язык вашего резюме, чтобы оно оставило неизгладимое впечатление «[8]; «Language matters in a resume / Язык имеет значение в резюме «[9].

Резюме, представляющее своего рода фрейм, навязывающий реципиенту развертывание концепта ЕМPLOYEE [1], использует все доступные в данном формате лексико-грамматические средства для конструирования образа идеального кандидата на ту или иную должность.

Целью работы является анализ специфики отбора лексики и грамматических форм, участвующих в вербализации концепта EMPLOYEE в шаблонах резюме англоязычного бизнес-дискурса.

\section{Задачи:}

1. на основании анализа шаблонов резюме и сопровождающих их экспертных статей в англоязычном сегменте сети Интернет определить специфику выбора лексических единиц при составлении резюме;

2. исследовать характеристики языковых единиц, рекомендованных к использованию, выделить преобладающие морфологические и грамматические формы; 
3. интерпретировать полученные данные в соответствии с представлением о структуре концепта EMPLOYEE.

Развитие технологий привело к распространению шаблонов резюме, дизайн которых позволяет заменять слова и предложения на графические символы. Однако пиктограммы и видеофайлы не скоро смогут полностью вытеснить текстовые job application. Одна из причин возрастающей важности каждого слова в резюме - первичная обработка CV с помощью специальных программ (applicant tracking systems): чтобы пройти этот фильтр, оно должно содержать keywords / ключевые слова, заявленные в объявлении о вакансии или же неопубликованные, но заложенные в программу самим рекрутером.

Однако главным реципиентом остается менеджер по найму, принимающий решение о том, попадет ли резюме на рабочий стол к потенциальному работодателю или отправится в мусорную корзину. Считается, что на принятие этого решения сотрудник в среднем тратит не более 6-10 секунд [7].

Для того, чтобы захватить внимание рекрутера (grab attention), эксперты рекомендуют использовать все имеющиеся в арсенале языковые и графические средства.

С одной стороны, резюме должно быть четко структурировано и форматировано, выдержано в нейтральной стилистике делового сообщения. С другой стороны, CV следует быть оригинальным, выделяться на фоне остальных подобных документов.

Автор резюме вынужден придерживаться установленных правил и шаблонов, максимально используя имеющиеся лексико-грамматические средства воздействия на реципиента.

В целях экономии текстового пространства в первую очередь сокращению подвергаются личные местоимения. Экономия места на странице - не единственная причина отказа от личных местоимений в резюме: «Once you've said "I", you're going to have to repeat it. A lot. "I did this, I did that, I did something else"... it soon starts to sound boring and egocentric. It'salsomainlyusedonthemost juniorCVs. / Как только вы сказали "я", вам придется повторить это. Много раз. "Я сделал это, я сделал то, я сделал что-то еще"... это скоро начинает звучать скучно и эгоцентрично» [12].

Цель соискателя - заявить о себе как об отличном специалисте, однако следует соблюдать меру и не демонстрировать чрезмерное самолюбование, хвастовство и эгоцентричность:

"Don'tusesubjectivewords. "I'm amazing at", "I'm incredible at" aren't as pleasing to hear as you might think. These statements make you appear self-involved, which recruit- ers find appalling / Не употребляйте субъективных слов. "Я потрясающе умею", "Я невероятно умею" - это не так приятно слышать, как вы могли бы подумать. Эти заявления заставляют вас казаться эгоистичными, вербовщики находят это ужасным» [9]. По этой причине устаревшими считаются резюме, содержащие секции Personal qualities, бездоказательно перечисляющие превосходные личные качества кандидата.

Гораздо более информативной является секция Јob Experience /Опыт работы, в которой эксперты рекомендуют использовать слова действия /action words (action verbs/ глаголы действия или power words / слова силы).

Применение action words без личного местоимения в форме Past Simple Active (worked, planned, organized / работал, планировал, организовывал) вместо герундия (working, planning, organizing / работа, планирование, организация) позволяет кандидату заявить о реальных действиях, которые он лично выполнял на предыдущей работе, избегая повторения местоимения "I". Графически эти глаголы часто оформляются в виде маркированного списка (bullets), что позволяет структурировать текст и облегчает его восприятие.

Эксперты настаивают на активном залоге: «You must use the active voice in order to take responsibility for your actions and prove you get results/ Вы должны использовать активный залог, чтобы взять на себя ответственность за свои действия и доказать, что вы получаете результаты «[11].

При этом следует заменять слишком часто используемые клишированные глаголы (led, worked, developed): «Some words are more exciting than others. Verbs, for example, are more engaging than nouns. And fresh verbs are the most exciting of all / Некоторые слова волнуют больше, чем другие. Глаголы, например, более привлекательны, чем существительные. А свежие глаголы самые волнующие из всех « [8].

Глаголы, используемые для описания опыта работы, должны не просто поражать оригинальностью. За ними стоит характеристика кандидата как специалиста в определенной области (industry-specificverbs: published, coded, transcribed), способного управлять другими (реоple management verbs: coached, directed, guided), paботать в команде (team work verbs: joined, united, blended), добиваться своих целей (goal oriented verbs: expended, reached,raised), обладающего креативностью (creation verbs: crafted, designed, invented)66, аналитическими способностями (examined, evaluated, verified) и навыками коммуникации (presented, negotiated, moderated) [4].

Подобный подход позволяет доказать наличие у кандидата hardskills и softskills (жестких/профессиональных 
и гибких, надпрофессиональных навыков), необходимых современному специалисту. "Hard skills are teachable and measurable abilities, such as writing, reading, math or ability to use computer programs. By contrast, soft skills are the traits that make you a good employee, such as etiquette, communication and listening, getting along with other people / Жесткие навыки - это способности, которым можно научиться и которые можно измерить, такие как письмо, чтение, математика или умение пользоваться компьютерными программами. Напротив, гибкие (мягкие) навыки - это черты, которые делают вас хорошим сотрудником, такие как этикет, общение и умение слушать, ладить с другими людьми» [5]. Отчет Linkedln «GlobalTalentTrends» о Глобальных тенденциях талантов за 2019 год показал, что 92\% специалистов по талантам и менеджеров по найму говорят, что гибкие навыки так же важны - или даже важнее - чем жесткие. Креативность, способность убеждать и навыки сотрудничества являются тремя наиболее востребованными надпрофессиональными навыками для компаний сегодня. По мере того как технологии все быстрее автоматизируют жесткие навыки, движущая сила спроса на сотрудников, способных мыслить нестандартно, ориентироваться в изменениях и хорошо работать с другими, становится все более важной [10].

Описание опыта работы с помощью глаголов действия помогает кандидату продемонстрировать наличие у него столь необходимых в современном мире навыков и сообщить об измеряемых достижениях в результате их применения:

Collaborated and communicated daily with a marketing team of 15 people. Gave monthly progress presentations to the team/ Ежедневно сотрудничал и общался с маркетинговой командой из 15 человек. Проводил ежемесячные презентации прогресса для команды [2].

Однако все увеличивающийся поток job applications уменьшает вероятность того, что менеджер по подбору персонала захочет прокручивать текст и вчитываться в резюме. Эксперты советуют располагать самую важную информацию в самом начале CV, после персональных данных, в разделе саммари - resume personal statement (professional summary, career objective): «lt sums up your experience, goals and skills with confidence. Think of your resume's personal statement like an extended tagline for your career / Оно уверенно суммирует ваш опыт, цели и навыки. Подумайте о личном заявлении (саммари) вашего резюме как о расширенном слогане для вашей карьеры» [2]. Считается, что рекрутер может принять решение на основе основной информации, поданной в начале резюме в максимально сжатой форме, тем самым сэкономив время на прокручивании текста вниз.

Саммари может быть написано от первого лица, но без употребления личного местоимения «l» В «телеграфном стиле»: «Innovative Executive Assistant with 10+ years of experience with global financial firm assisting a team of three C-Level directors. Expertly coordinate travel, manage largescale expense reports, and streamline communication and calendars across departments. Seeking an Executive Assistant role with the Resume.ioteam to expand my office management career and thrive in an environment that requires independent problem-solving skills and focus under short deadlines (здесь и далее выделено мной - П.А. ) / Инновационный исполнительный помощник с более чем 10-летним опытом работы в глобальной финансовой фирме, помогающий команде из трех директоров уровня С. Умело координирую поездки, управляю крупномасштабными отчетами о расходах и оnтимизирую коммуникацию и календарные планы междуотделами. Ищу должность исполнительного помощника с Resume.ioteam чтобы расширить мою карьеру офисного менеджера и преуспеть в среде, которая требует независимых навыков решения проблем и сосредоточенности в сжатые сроки [2].

Однако такое представление кандидата может быть написано и от третьего лица: "Award-winning software developer in the gaming industry, having worked on three of the biggest MMORPG titles in the last decade, seeking a second freelance role alongside current work with Trackvision. Offers knowledge of 8 languages and all major design software, code editors and testing tools / Удостоенный наград разработчик программного обеспечения В игровой индустрии, работавший над тремя крупнейшими MMORPG-играми запоследнее десятилетие, ищет вторую внештатную роль наряду с текущей работой с Trackvision. Предлагает знание 8 языков и всех основных программ проектирования, редакторов кода и инструментов тестирования [2].

Среди экспертов нет единого мнения, какой вариант предпочтительнее. Так, резюме от первого лица более естественно. "(Я) успешный менеджер по продажам" звучит разумно, легко пишется и представляет кандидата как реального человека. Однако письмо от третьего лица «привносит намек на формальность, делая документ более отшлифованным и профессиональным. В таком написании резюме есть свои преимущества - в конце концов, бизнес-это не личное. Рекрутер хочет нанять кого-то, кто может обеспечить правильные результаты для компании, поэтому менее личный стиль позволяет читателю сосредоточиться на ценности, которую вы можете добавить, а не на ваших личных качествах « [6].

Таким образом, в современном эффективном резюме не существует ни одного случайного слова или символа. Отбор языковых средств детерминирован предполагаемыми особенностями восприятия реципиента на первичном этапе обработки, в роли которого все чаще выступает компьютерная программа. Основной объект языковой суггестии - сотрудник, осуществляющий ана- 
лиз резюме. При этом необходимо учитывать как устоявшийся канон делового общения, так и высокую конкуренцию с другими однотипными текстами.

Особенностью вербализации концепта EMPLOYEE в шаблонах резюме англоязычного бизнес-дискурса является доминирование глаголов, составляющих ядро текста. В синтаксическом плане резюме можно представить как одно предложение, в котором роль субъекта выполняет раздел Personal Details. Отсутствие личных местоимений - одна из характерных лексико-грамматических особенностей языка резюме, обусловлена экономящим пространство «телеграфным стилем», а также намерением автора создать единый объективизированный образ высококлассного специалиста: активно действующего, принимающего на себя ответственность (использование форм первого/третьего лица глаголов в Present (Past) Simple Active / Participle I /Perfect Pearticiple), но избегающего бездоказательного самовосхваления и чрезмерной самоуверенности. Выбор определенных глаголов из синонимического ряда призван продемонстрировать наличие ключевых профессиональных и надпрофессиональных (гибких) навыков у заявителя.

\section{ЛИТЕРАТУРА}

1. Пашина А.В., Омелаенко Н.В., Денеко М.В. Специфика вербализации концепта EMPLOYEE в шаблонах резюме англоязычного бизнес-дискурса // Современная наука: актуальные проблемы теории и практики. Серия: Гуманитарные науки. -2019. -№10. - С. 160-164

2. Bax R. How to write a resume personal statement // Resume.io [Электронный ресурс]. - Режим доступа: https://resume.io/how-to-write-a-resume/resumepersonal-statement (дата обращения: 15.03.2021).

3. Collins D. The 500-year evolution of the resume// Insider [Электронный ресурс]. - Режим доступа: https://www.businessinsider.com/how-resumes-haveevolved-since-their-first-creation-in-1482-2011-2 (дата обращения: 17.03.2021).

4. Emmet S. Make your resume strong by using right words // ТорСV [Электронный ресурс]. - Режим доступа: https://www.topcv.com/career-advice/actionwords-for-cv (дата обращения: 15.03.2021).

5. Gerencer T. Hard Skills vs Soft Skills: List of Best Examples for the Workplace// Zety.com [Электронный ресурс]. - Режим доступа: https://zety.com/blog/hardskills-soft-skills (дата обращения: 17.03.2021).

6. Hunter M. Ask a recruiter:Should your resume be written in 1st or 3rd person? Morganhunter.com [Электронный ресурс]. - Режим доступа: https://www. morganhunter.com/2020/11/03/ask-a-recruiter-should-your-resume-be-written-in-1st-or-3rd-person (дата обращения: 17.03.2021).

7. Ladders - Eye Tracking - Study С2 [Электронный ресурс]. - Режим доступа: https://www.theladders.com/static/images/basicSite/pdfs/TheLadders-EyeTrackingStudyC2.pdf (дата обращения: 17.03.2021).

8. Navins M. 400+ Resume action words (Plus 100 Power words Recruiters love to see)//Jobcan.co [Электронный ресурс]. - Режим доступа: https://www.jobscan. co/blog/resume-action-words (дата обращения: 17.03.2021).

9. 340+ Resume Action Verbs \& Power Words [For 2021]//Novoresume.com [Электронный ресурс]. - Режим доступа: https://novoresume.com/career-blog/top10-most-powerful-action-words-for-resume (дата обращения: 17.03.2021).

10. Shappeley J. Linkedln reseach reveals the value of soft skills//Fast Company.com [Электронный ресурс]. - Режим доступа: https://www.fastcompany. com/90298828/linkedin-research-reveals-the-value-of-soft-skills (дата обращения: 17.03.2021).

11. Using the «Active Voice» in Your Resume//Artisan Creative [Электронный ресурс]. - Режим доступа: https://www.artisancreative.com/using-the-active-voicein-your-resume/\#: :text=Using\%20the\%20passive\%20voice\%20—\%20where,not\%20impactful\%20on\%20a\%20resume.\&text=You\%20must $\% 20$ use $\% 20$ the\%20active,and\%20prove\%20you\%20get\%20results (дата обращения: 17.03.2021).

12. Waters M. Do you always write a CV/Resume in the third person? Quora [Электронный ресурс]. - Режим доступа: https://www.quora.com/Do-you-alwayswrite-a-CV-Resume-in-the-third-person (дата обращения: 20.03.2021).

13. Your Resume Should NOT Use the Word "I" ... and other tricks of the trade//Solutions for the workplace.com [Электронный ресурс]. - Режим доступа: https:// solutionsfortheworkplace.com/your-resume-should-not-use-the-word-i-and-other-tricks-of-the-trade/\#: :text=Resumes\%20are\%20appropriately\%20 written\%20in,our\%2C\%20etc.\%2C\%20either. (дата обращения: 15.03.2021).

(c) Пашина Алёна Владимировна (pashinaav@tyuiu.ru).

Журнал «Современная наука: актуальные проблемы теории и практики» 